\title{
Rare de novo inversion-duplication case with pure 3qter duplication syndrome including an overlap of the dup(3q) critical region: A case report
}

\author{
GEORGE IMATAKA $^{1}$, YOSHIYUKI WATABE ${ }^{1}$, SAYURI KAJITANI $^{1}$, SHUN WATANABE $^{2}$, \\ JUNKO ICHIKAWA $^{1}$, FABRIZIO DRAGO ${ }^{3}$, HIROSHI SUZUMURA ${ }^{1}$ and SHIGEMI YOSHIHARA ${ }^{1}$ \\ ${ }^{1}$ Department of Pediatrics and ${ }^{2}$ First Department of Surgery, Dokkyo Medical University, Tochigi 321-0293, Japan; \\ ${ }^{3}$ Department of Pediatric Cardiology and Cardiac Surgery, Pediatric Cardiology and Cardiac Arrhythmias Complex Unit, \\ Bambino Gesù Children's Hospital and Research Institute, I-00050 Rome, Italy
}

Received March 8, 2017; Accepted April 18, 2017

DOI: $10.3892 /$ etm.2017.4416

\begin{abstract}
We report here a very rare case of de novo inversion-duplication chromosomal abnormality with a pure 3 qter duplication syndrome. Interestingly, the $3 q$ duplication includes an overlap of the syndrome's critical region. Although there have only been 9 cases of this syndrome reported in the past, our patient had more severe neurological abnormalities than anticipated. In this regard, we have gathered the $3 \mathrm{q}$ chromosomal duplication abnormalities known to cause pure $3 q$ duplication syndrome to date as a reference for comparisons and we discuss the particulars of our case.
\end{abstract}

\section{Introduction}

Pure chromosome $3 q$ duplications are very rare. Most of the reported cases with a $3 q$ duplication syndrome are thought to occur from parental unbalanced translocations (1). Here we report the case of a little girl with a very rare chromosomal abnormality consisting of pure duplication of 3 qter due to a mechanism of de novo inversion(3)-duplication and its associated clinical syndrome.

\section{Case report}

The mother of the unborn baby had been hospitalized since the middle of her pregnancy due to premature labor risk signs. The fetus was diagnosed with ventricular enlargement by ultrasonic examination. The female neonate was born through vaginal delivery at 31 weeks and 2 days of the maternal pregnancy. Her birth weight was $1,308 \mathrm{~g}$. Asphyxia was noted at birth.

Correspondence to: Dr George Imataka, Department of Pediatrics, Dokkyo Medical University, 880 Kitakobayashi, Shimotsuga, Mibu, Tochigi 321-0293, Japan

E-mail: geo@dokkyomed.ac.jp

Key words: 3q, duplication syndrome, congenital anomaly
Also, multiple anomalies were recognized at birth including hypertelorism, wide nasal bridge, micrognathia, cleft palate and lips, low-set ears and dysmorphic fingers. A large soft hemangioma was localized on the occipital region of the head. Cardiac ultrasonography confirmed a ventricular septal defect muscular region of $2 \mathrm{~mm}$ in diameter. The baby also presented congenital hearing loss confirmed by tests. Oral feeding with milk was difficult due to stenosis of the throat and the tongue settlement, and it became necessary to provide the infant with a feeding tube. Unfortunately, aspiration pneumonia associated with gastro-esophageal reflux occurred and the infant had to be placed under long term-artificial ventilation therapy.

At the time, the parents were provided genetic counseling; after which chromosomal examination revealed the infant's karyotype as 46 XX, dup(3)(q29q22) (Fig. 1). Motor and intellectual developments were delayed and at 6-months of age, the infant was still unable to stabilize her head and neck in the upright position. Brain magnetic resonance imaging (MRI) showed evidence of delayed myelination and agenesis of the corpus callosum (Fig. 2). No further abnormalities were noted until the little girl became two years old, then a diagnosis of developmental retardation was given and a gastrostomy line had to be established for her daily nutrition.

\section{Discussion}

There are three types of mechanisms by which $3 \mathrm{q}$ partial trisomy occurs. In one, an inversion(3) in a parent's chromosome $3 \mathrm{q}$ becomes the recombinant chromosome. In another, the defect is caused by a parental unbalanced translocation. And finally, a last possible mechanism involves partial chromosome duplication with de novo-inversion. In recombinant chromosomes with translocations, there are many cases where partial monosomy by a chromosome different from that involved in the partial trisomy chromosome is also present. Many of the papers previously reported on $3 q$ trisomy syndrome included partial monosomies in chromosomes other than the $3 q$ chromosome involved in the partial trisomy (1).

Our case is special in that the $3 \mathrm{q}$ partial trisomy is caused only by de novo $3 \mathrm{q}$ inversion-duplication. The chromosomal 

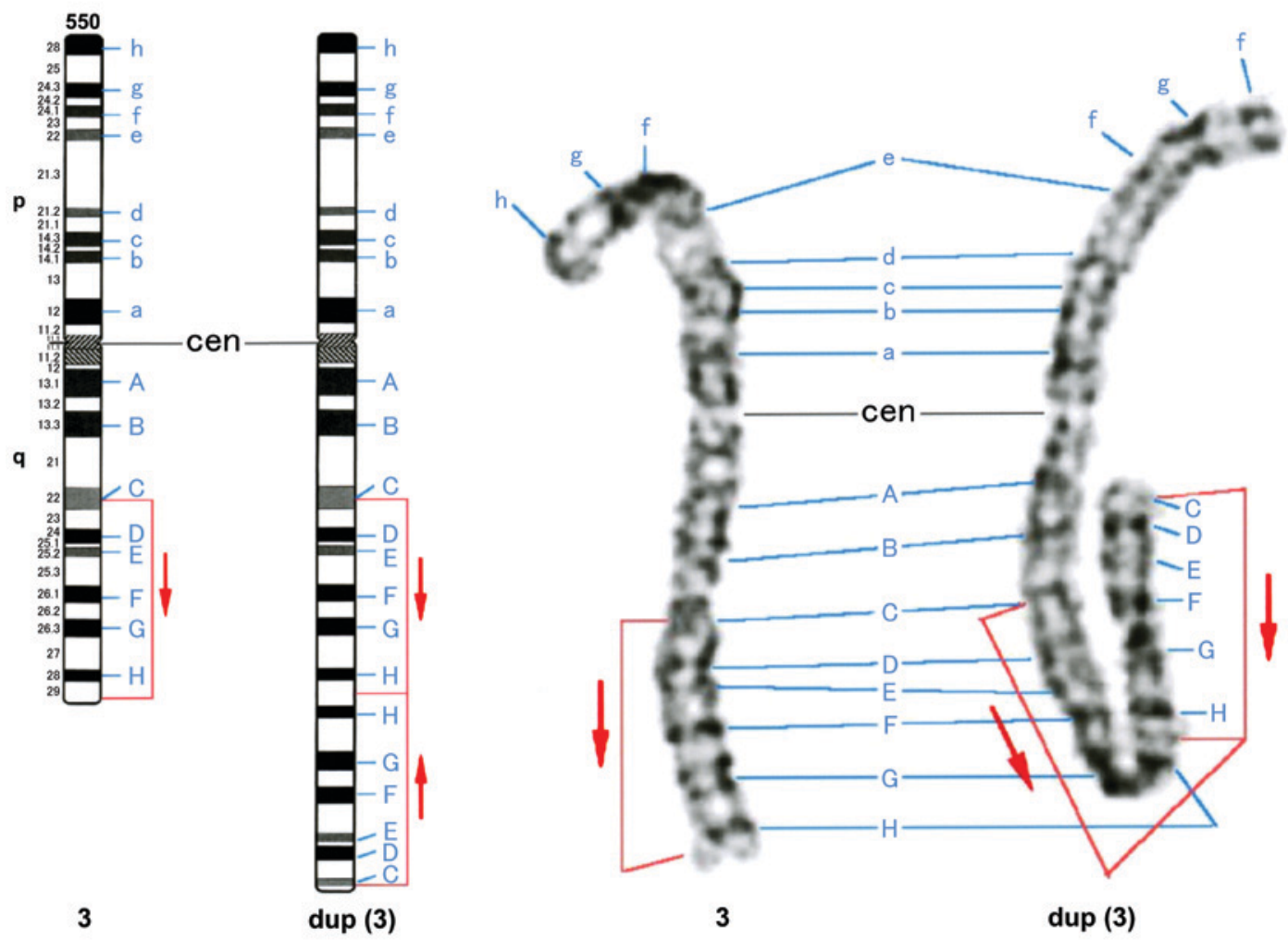

Figure 1. Chromosomal analysis with high resolution band stain, employing fifteen cells. Stain band level is 550. The karyotype of the patient revealed $\operatorname{dup}(3)(\mathrm{q} 29 \mathrm{q} 22)$.

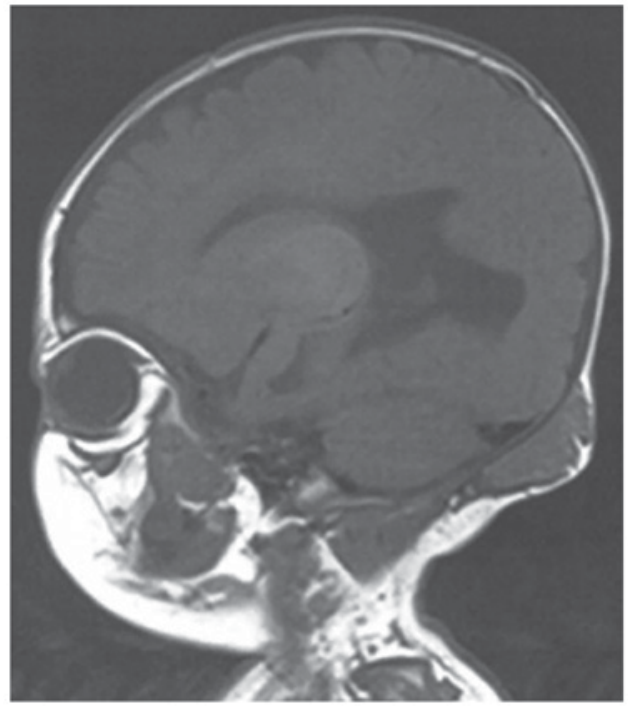

Figure 2. Sagital MRI image of the 6-month-old patient showing delayed myelination, agenesis of the corpus callosum and non-involuting congenital posterior hemangioma. Spin echo method (echo time, $13.00 \mathrm{msec}$; repetition time, $700.00 \mathrm{msec}$ ) T1-weighted sagittal brain MRI. MRI, magnetic resonance imaging.

karyotype of our patient is $46 \mathrm{XX}$, dup(3)(q29q22), which can be classified as a pure $3 \mathrm{q}$ duplication (since it does not involve excess or deficiency of other chromosomal fragments). Our report is a very valuable source of information for the clinical syndrome resulting from pure $3 \mathrm{q}$ duplication, given the scarcity of such cases. Furthermore, the etiology of many of the reported $3 \mathrm{q}$ duplication syndromes is duplication of

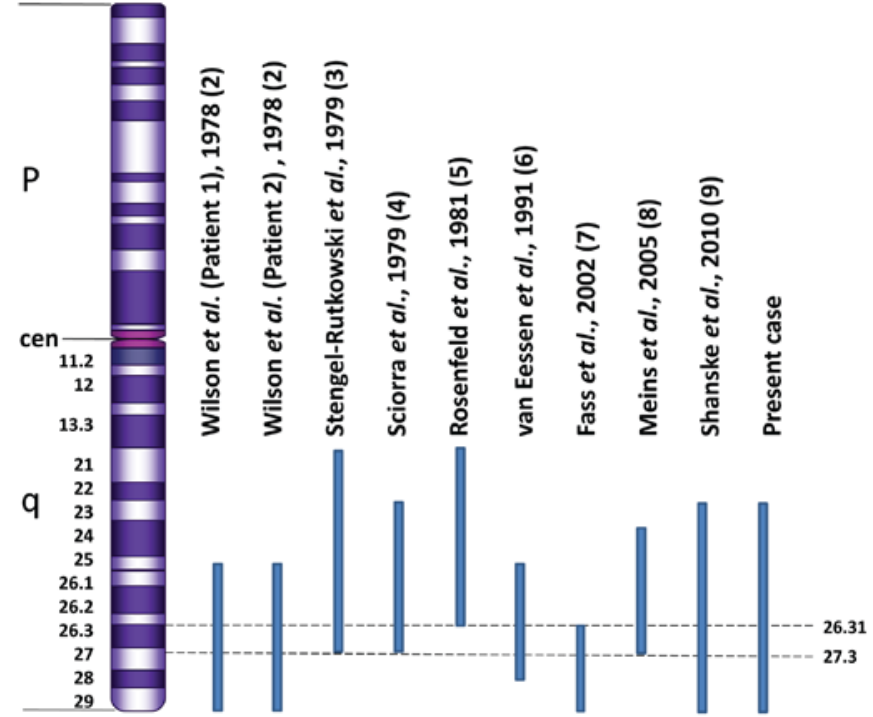

Figure 3. Overview of the chromosomal abnormalities in all the reported pure $3 \mathrm{q}$ duplication syndrome cases found. A critical region of $3 \mathrm{q}$ duplication at the chromosomal 3q26.31-q27.3 region is essential for the characteristic clinical phenotype.

$3 q 21 \rightarrow q$ ter, and to the best of our knowledge only 9 individuals with pure $3 \mathrm{q}$ duplication syndrome have been reported in the literature (2-9). Our case represents the 10th case; Fig. 3 for a graphic comparison of the partial 3q trisomy in our case with the others available. In pure $3 q$ duplication syndrome, it is not necessary to consider the monosomy of another chromosomal fragment when analyzing the etiology of phenotypic clinical 
features. Thus, careful comparison of the clinical features described in other pure $3 q$ duplications can help elucidate the influence of specific gene critical regions on the phenotype. Faas et al reported a de novo $3 \mathrm{q}$ duplication syndrome with descriptions of 6 other previous cases and concluded that a critical region responsible for the $3 q$ duplication phenotype could be assigned to $3 \mathrm{q} 26.31-\mathrm{q} 27.3$ (7). In this study, our case was analyzed in view of the previous reports; our $3 q$ partial trisomy overlaps with the described critical region on chromosome 3. Moreover, the severity of the motor and intellectual deficiencies in our case is uncommon. This may be due to the specific chromosomal fragments involved in the inversionduplication in our case when compared to the syndromes described in past reported cases (2-8). More cases should be examined in the future in order to fully understand the characteristics of pure $3 q$ duplication syndrome.

\section{References}

1. Koç A, Ekmekci AY and Ozer O: A case of dup(3q) syndrome. Genet Couns 24: 381-385, 2013.

2. Wilson GN, Hieber VC and Schmickel RD: The association of chromosome 3 duplication and the Cornelia de Lange syndrome. J Pediatr 93: 783-788, 1978.
3. Stengel-Rutkowski S, Murken JD, Pilar V, Dutrillaux B Rodewald A, Goebel R and Bassermann R: New chromosomal dysmorphic syndromes. 3. Partial trisomy 3q. Eur J Pediatr 130: 111-125, 1979.

4. Sciorra LJ, Bahng K and Lee ML: Trisomy in the distal end of the long arm of chromosome 3 . A condition clinically similar to the Cornelia de Lange syndrome. Am J Dis Child 133: 727-730, 1979.

5. Rosenfeld W, Verma RS, Jhaveri RC, Estrada R, Evans H, Dosik H and Opitz JM: Duplication 3q: severe manifestations in an infant with duplication of a short segment of 3q. Am J Med Genet 10: 187-192, 1981.

6. van Essen AJ, Kok K, van den Berg A, de Jong B, Stellink F, Bos AF, Scheffer $\mathrm{H}$ and Buys $\mathrm{CH}$ : Partial 3q duplication syndrome and assignment of D3S5 to 3q25-3q28. Hum Genet 87: 151-154, 1991.

7. Faas BH, De Vries BB, Van Es-Van Gaal J, Merkx G, Draaisma JM and Smeets DF: A new case of $\operatorname{dup}(3 \mathrm{q})$ syndrome due to a pure duplication of 3qter. Clin Genet 62: 315-320, 2002.

8. Meins M, Hagh JK, Gerresheim F, Einhoff E, Olschewski H, Strehl H and Epplen JT: Novel case of dup(3q) syndrome due to a de novo interstitial duplication 3q24-q26.31 with minimal overlap to the $\operatorname{dup}(3 q)$ critical region. Am J Med Genet A 132A: 84-89, 2005.

9. Shanske AL, Leonard J, Nahum O, Coppock DL and Levy B: Delineation of the breakpoints of pure duplication $3 q$ due to a de novo duplication event using SOMA. Am J Med Genet A 152A: 3185-3188, 2010 . 